\title{
A INFLUÊNCIA DAS CONDIÇÕES GEOQUÍMICAS NA OXIDAÇÃO DA ARSENOPIRITA E NA MOBILIDADE DO ARSÊNIO EM AMBIENTES SUPERFICIAIS TROPICAIS
}

\author{
RICARDO PEROBELLI BORBA ${ }^{1} \&$ BERNARDINO RIBEIRO FIGUEIREDO $^{2}$
}

\begin{abstract}
THE INFLUENCE OF GEOCHEMICAL CONDITIONS ONARSENOPYRITE OXIDATIONAND ON THE MOBILITY OF ARSENIC IN TROPICAL SURFACE ENVIRONMENTS Geochemical processes that govern weathering conditions of auriferous deposits in the Iron Quadrangle, Minas Gerais, Brazil were studied through X-Ray Diffraction analysis, Scanning Electronic Microscopy, and chemical analysis of groundwater collected in mines. Natural oxidation of arsenopyrite in quartz-arsenopyrite veins (without carbonates) promotes the formation of scorodite, while the oxidation of arsenopyrite in veins of quartz-carbonates-arsenopyrite leads to the formation of low-crystalline iron arsenates which contains $\mathrm{Ca}$, and in smaller amounts, the formation of scorodite, kolfanite, yukonite, and farmacossiderite. The release of As to surface and groundwaters occurs in steps: (i) during the oxidation of arsenopyrite a fraction of As is solubilized and another fraction participates in the formation of iron arsenate or scorodite, (ii) during total or incongruent dissolution of secondary As minerals there is retention of a fraction of arsenic adsorbed in iron oxide and another fraction is solubilized. The presence of carbonates in sulfurous mineral deposits neutralizes acid drainage formed from the oxidation of sulfides. However, in the case of As, neutral to alkaline $\mathrm{pH}$ induces its release into solution by dissolution of iron arsenates and scorodite, increasing As mobility in a surface environment.
\end{abstract}

Keywords: arsenopyrite, oxidation, scorodite, kolfanite, yukonite, farmacossiderite arsenic, mobility, gold, Iron Quadrangle

\begin{abstract}
Resumo Os processos geoquímicos que regem o intemperismo de depósitos auríferos do Quadrilátero Ferrífero, MG foram estudados por difração de raios X, microscopia eletrônica de varredura, e análises químicas de águas subterrâneas coletadas em minas. A oxidação natural da arsenopirita em veios de quartzo-arsenopirita (sem carbonatos) promove a formação de escorodita enquanto que em veios de quartzo-carbonatos-arsenopirita a oxidação da arsenopirita leva à formação de arsenatos de ferro com Ca, com cristalinidade baixa, e em menor quantidade, à formação de escorodita, kolfanita, yukonita e farmacossiderita. A liberação do As para as águas superficiais e subterrâneas ocorre por etapas: (i) durante a oxidação da arsenopirita parte do As é solubilizado e outra parte participa da formação de arsenato de ferro ou escorodita, (ii) durante a dissolução total ou incongruente dos minerais secundários de As ocorre a retenção de parte do arsênio adsorvido em óxido de ferro e outra parte é solubilizada. A presença de carbonatos nos minérios sulfetados neutraliza a drenagem ácida, formada a partir da oxidação dos sulfetos. Entretanto, no caso do As, o pH neutro a alcalino induz a liberação do As em solução através da dissolução do arsenatos de ferro e da escorodita, aumentando sua mobilidade em ambiente superficial.
\end{abstract}

Palavras-chave: arsenopirita, oxidação, escorodita, kolfanita, yukonita, farmacossiderita, arsênio, mobilidade, ouro, Quadrilátero Ferrífero

INTRODUÇÃO O Arsênio forma mais de 200 minerais como principal constituinte (óxidos, arsenetos, sulfetos, e arsenatos), que se concentram principalmente em áreas mineralizadas; a arsenopirita é o mineral de As mais comum das mineralizações (Smedley \& Kinniburgh 2002). A liberação do As a partir das rochas mineralizadas se dá via oxidação da arsenopirita por $\mathrm{O}_{2}$ ou $\mathrm{Fe}^{3+}$ (Plumlee 1999), através de processos inorgânicos ou bióticos (Nordstron \& Southam 1997). A solubilização dos oxianions de As presentes na superfície oxidada da arsenopirita (Nesbitt et al. 1995) dá origem aos ácidos arsenioso $\left(\mathrm{H}_{3} \mathrm{AsO}_{3}\right)$ e arsênico $\left(\mathrm{H}_{3} \mathrm{AsO}_{4}\right)$ e suas espécies deprotonadas, i.e., $\mathrm{H}_{2} \mathrm{AsO}_{4}, \mathrm{HAsO}_{4}{ }^{2-}$, $\mathrm{AsO}_{4}{ }^{3-}$ (ín arsenato) $\mathrm{e}_{2} \mathrm{AsO}_{3}, \mathrm{HAsO}_{3}^{2-}, \mathrm{AsO}_{3}^{3-}$ (íon arsenito). Em condições de $\mathrm{pH}$ neutro a levemente ácido o As solubilizado, preferencialmente o íon arsenato (Bowell 1994), pode ser retido no solo ou em rochas intemperizadas através da adsorção em óxidos de ferro e argilo-minerais ou co-precipitação com óxidos de ferro (Dzombak \& Morel 1990; Manning \& Goldberg 1996, 1997).

Nas rochas, solos ou pilhas de rejeito a oxidação da arsenopirita pode dar origem a escorodita, provavelmente o arsenato mais co- mum (Alpers et al. 1994); em meio alcalino pode ocorrer a formação de arsenatos de Ca (Julliot et al. 1999), de Mg (Voigt et al. 1996) e provavelmente de Fe e Ca. Em solos tropicais de Ghana (África), a oxidação da arsenopirita deu origem a minerais secundários de As como bukovskyta, escorodita, kankita e pitticita, e arsênio dissolvido, na forma de arsenato, nas soluções dos poros dos solos (Bowell et al. 1994) e no aquífero a $70 \mathrm{~m}$ de profundidade (Smedley 1996). No México, em aqüíferos fraturados hospedados em rochas carbonáticas, cortadas por mineralizações sulfetadas, a oxidação da arsenopirita e dissolução da escorodita promoveram a liberação de As e contaminação natural do aquífero (Armienta et al. 2001).

Embora se conheçam alguns mecanismos de oxidação da arsenopirita e de formação dos minerais secundários de As, trabalhos sobre os processos geoquímicos envolvidos nestas transformações e a liberação de As em solução associada a elas, são raros ou mesmo inexistentes na literatura.

Neste estudo foi realizada uma investigação comparativa dos processos de oxidação da arsenopirita em ambiente superficial

1 - Instituto Agronômico, CP 28 - Cep 13.020-902 - Campinas - São Paulo Brasil; borba@iac.sp.gov.br

2 - Instituto de Geociências, Unicamp, CP 6152 - Cep 13.083-970 - Campinas - São Paulo Brasil; berna@ige.unicamp.br 
tropical, no Quadrilátero Ferrífero, com diferentes características geoquímicas, i.e., rochas mineralizadas pobres e ricas em carbonatos, e as relações destes processos de oxidação com: (i) os minerais secundários formados e (ii) a retenção e liberação de As nas águas subterrâneas.

CARACTERIZAÇÃO GEOLÓGICA DOS LOCAIS DE COLETA DE AMOSTRAS E DE OCORRENCIA DE ARSENOPIRITA O Quadrilátero Ferrífero é uma região com inúmeras jazidas auríferas sulfetadas exploradas há mais de 300 anos. Quatro unidades litoestratigráficas principais compõem o Quadrilátero Ferrífero: os complexos metamórficos granitognaissicos, uma seqüência greenstone belt arqueana denominada de Supergrupo Rio das Velhas, os metassedimentos e metavulcânicas Proterozóicas do Supergrupo Minas, e os metassedimentos do Grupo Itacolomi (Dorr 1969). A arsenopirita ocorre nos veios mineralizados dos depósitos auríferos, que estão hospedados nas rochas dos Supergrupos Rio das Velhas e Minas.

Os depósitos auríferos localizados nas cidades de Ouro Preto e de Mariana, nos distritos de Passagem e Antônio Pereira, ocorrem em superfície e subsuperfície, muitos dos quais tem a arsenopirita como principal sulfeto (Fig.1). Na cidade de Ouro Preto, o depósito aurífero situado superficialmente nas Lages ocorre em veios verticais de quartzo, arsenopirita e turmalina que cortam os quartzitos basais do Supergrupo Minas (Cavalcanti 1999). Na mina do Chico Rei, situada topograficamente abaixo das Lages, depósito aurífero também ocorre em metassedimentos Proterozóicos do Supergrupo Minas. As principais unidades estratigráficas da mina do Chico Rei possuem o seguinte empilhamento da base para o topo: quartzito, sericita xisto carbonoso e filito carbonoso, e itabiritos (silicoso, anfibolítico, carbonático). A zona mineralizada ocorre principalmente no filito carbonoso onde o minério está associado a turmalinito, veios de quartzo-arsenopirita com turmalina e mica branca (com porções maciças de arsenopirita), veios de quartzo-pirita-calcopirita e veio de quartzo bandado com arsenopirita (Cavalcanti 1999).

Em Mariana, segundo Ribeiro (1998), o depósito aurífero de Antônio Pereira ocorre, em superfície, na forma de veios constituídos por quartzo, dolomita e arsenopirita que cortam os mármores da Formação Gandarela (Supergrupo Minas). O depósito aurífero de Passagem esta situado numa seqüência litológica semelhante a encontrada na mina do Chico Rei, sendo suas rochas relacionadas aos metassedimentos Proterozóicos do Supergrupo Minas (Oliveira 1998). A sequiência litológica, da base para o topo é constituída por quartzito, filito negro, mármore com turmalinitos, metachert carbonático sulfetado bandado, rochas quartzo carbonáticas, mármores, muscovita-biotita-xisto e itabirito (Oliveira 1998). A zona mineralizada está hospedada principalmente nos filitos onde o depósito aurífero ocorre em turmalinitos, em veios quartzo-carbonáticos com sulfeto e em veios de quartzo com arsenopirita (Oliveira 1998). O principal sulfeto da mineralização é a arsenopirita; outros sulfetos presentes em quantidades subordinadas são a pirrotita, pirita, loellingita, calcopirita.

MATERIAIS E MÉTODOS Amostras de solo e rocha As amostras superficiais e sub-superficiais de rochas, frescas e intemperizadas, e de minerais/compostos químicos precipitados foram coletadas em veios e rochas em Ouro Preto (Lages e Mina do Chico Rei) e em Mariana (Antônio Pereira e Mina de Passagem). Foram coletadas pelo menos 20 amostras de rocha (fresca e intemperizada) em cada depósito aurífero, totalizando 118 amostras. Na amostragem foram coletadas cuidadosamente a rocha fresca e sua cobertura intemperizada ou somente a rocha intemperizada.

As amostras selecionadas foram secas a temperatura ambiente $\left(25^{\circ} \mathrm{C}\right)$. Uma parte de cada amostra foi cominuída manualmente em cadinho de porcelana, em alguns casos houve uma pré-concentração das porções de arsenopirita intemperizadas antes da cominuição. A composição mineralógica de 64 amostras foi de-

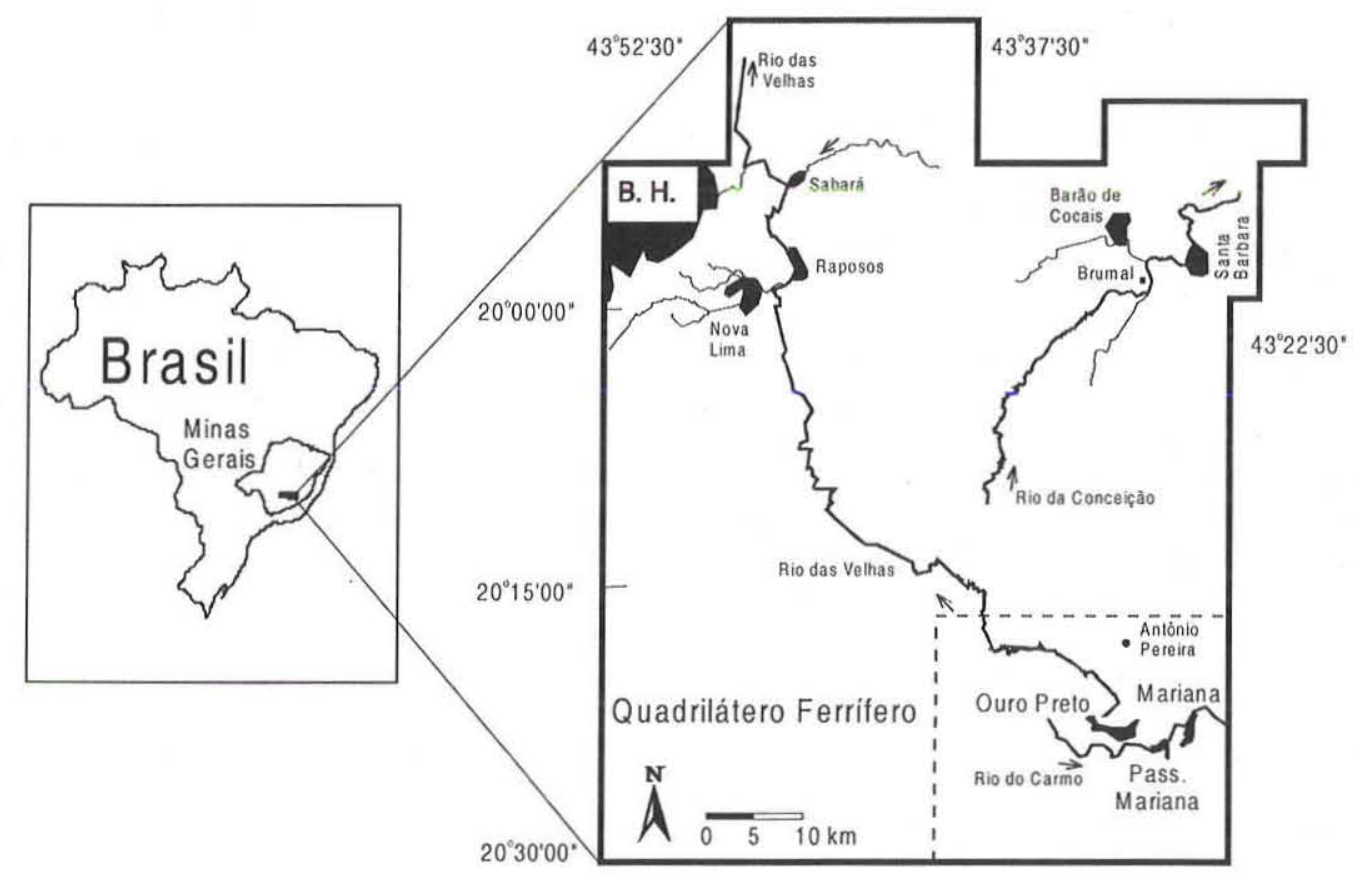

Figura I - Mapa de localização da área de estudo 
terminada por difratometria de raios- $x$ (DRX) no IGCE/UNESP. Quarenta das amostras selecionadas e analisadas por DRX, foram mantidas em estufa a $\mathrm{T}<50^{\circ} \mathrm{C}$ metalizadas e observadas por microscopia eletrônica de varredura (MEV) no IG/UNICAMP.

Amostras de água Em cada ponto de coleta foram medidos in situ o $\mathrm{pH}$, Eh, a condutividade e a temperatura. Foram coletadas quatro amostras de água por ponto. Três destas amostras foram filtradas através de uma membrana de acetato de celulose de 0,45 $\mu \mathrm{m}$ (Millipore ${ }^{\mathrm{R}}$ ). Uma das amostras foi mantida de modo natural para análise dos ânions, outras duas foram aciduladas com $0,2 \%$ de $\mathrm{HNO}_{3}$ P.A., para análise dos cátions e especiação de As. Nas amostras filtradas, os cátions e os ânions foram determinados por ICP-AES, no IQ/UNICAMP, e por cromatógrafo de íons no CEPAS/IGC/USP, respectivamente. A amostra não filtrada, de 500 $\mathrm{mL}$ foi utilizada para a determinação da alcalinidade do bicarbonato por titulação, usando ácido sulfúrico $(0,16 \mathrm{~N})$ e indicador verde de bromocresol. A especiação de $\mathrm{As}\left(\mathrm{As}^{3+} \mathrm{e} \mathrm{As}_{\text {Totan }}\right)$ foi feita por HG-AAS segundo o método de Borba et al. (2003).

RESULTADOS Estudos mineralógicos e microanálises Nas áreas mineralizadas os horizontes $\mathrm{A}$ e $\mathrm{B}$ do solo foram removidos quase totalmente pelos antigos exploradores em busca dos minérios oxidados e frescos; nas zonas mineralizadas encontra-se atualmente apenas o saprólito. Em subsuperfície foi possível encontrar tanto veios com arsenopirita completamente intemperizados (saprólito), como veios com minerais frescos apenas com uma pequena camada superficial de oxidação.

A ausência e a presença de carbonatos nos veios mineralizados e em suas rochas encaixantes é o principal fator diferenciador das características geoquímicas das ocorrências de arsenopirita. Nos veios superficiais das Lages e sub-superficiais da mina do Chico Rei, em Ouro Preto, o carbonato é praticamente inexistente, já nos veios e em suas rochas encaixantes tanto em superfície, no depósito aurífero de Antônio Pereira, como em subsuperfície, na mina de Passagem de Mariana, ambos em Mariana, os carbonatos são abundantes.

Ocorrências de arsenopirita sem carbonatos LAGES Em Ouro Preto, na localidade Lages, a atuação do intemperismo sobre os veios de quartzo e arsenopirita provocou a formação de uma camada pulverulenta amarelo-esverdeada e ocre sobre os mesmos, constituída por escorodita (Fig. 2 e Tabela 1).

No exame das amostras por MEV a superfície dos cristais de arsenopirita apresentou feições de dissolução como alvéolos (Fig.3). Apesar de não possuírem nenhum sinal aparente de oxidação alguns cristais de arsenopirita analisados por EDS possuíam em sua superfície o $\mathrm{O}$ além do $\mathrm{Fe}$, As e $\mathrm{S}$. Minerais secundários de arsênio, constituídos por FeAsOS em proporções variadas, recobrem os cristais de arsenopirita. A composição destes minerais secundários varia principalmente quanto à quantidade de $S$ presente: (i) as camadas dos minerais em placas que recobrem de modo uniforme a arsenopirita e que apresentam gretas de contração, devido à perda de água de hidratação adsorvida na superfície dos grãos durante a preparação das amostras para seu exame pelo MEV, possuem maiores teores de S, (ii) já os grânulos precipitados sobre o mineral secundário em placas e também diretamente sobre os alvéolos superficiais da arsenopirita e os cristais dendríticos possuem menos S (Fig.4).

MINA DE CHICO REI (ANTIGA MINA DA ENCARDIDEIRA) As rochas da mina do Chico Rei (MCR), especialmente os filitos grafitosos, os itabiritos e os veios mineralizados, estão intemperizados, representando um horizonte saprolítico. Por toda a mina existem escorrimentos de água pelas paredes e gotejamentos do teto; a água é drenada pela boca principal da mina.

Os veios bandados formados por quartzo e arsenopirita, encaixados em xistos e filitos, estavam recobertos por duas camadas de material precipitado: (i) uma camada vermelha (constituída por illita e escorodita) recobria diretamente o veio, e (ii) uma camada negra (formada por goethita e hematita) sobre a camada vermelha. Numa amostra do veio de arsenopirita maciça, com pequena porosidade, os cristais de arsenopirita foram substituídos por cristais de escorodita com textura maciça. A intensidade da substituição aumenta do centro para a borda da amostra (Fig. 5). Na superfície do veio os cristais de escorodita sofreram um processo de dissolução incongruente e foram substituídos por goethita (Fig. 2), que possui textura porosa. O exame pelo EDS mostrou além
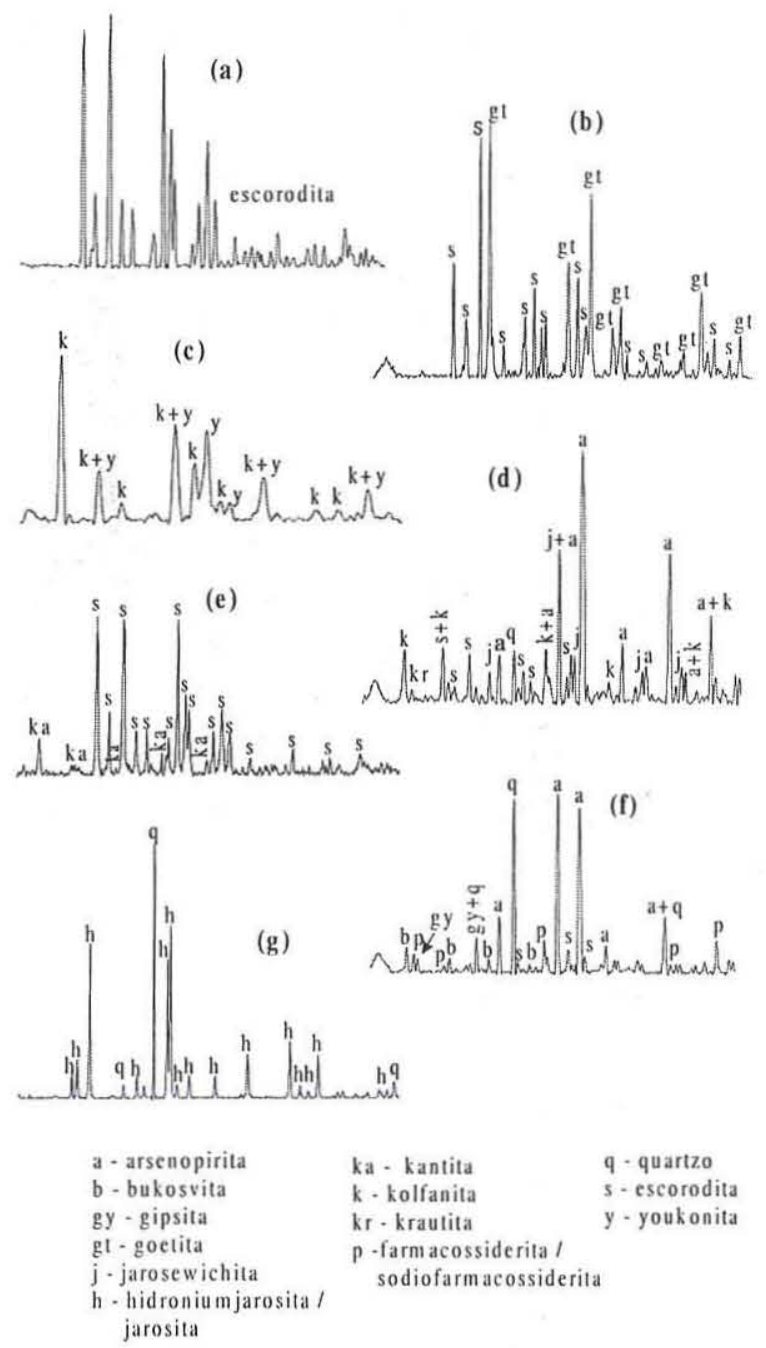

Figura 2 - Difratogramas de raios-x : a - veio superficial de quartzo-arsenopirita, Lages; $b$ - veio de quartzo-arsenopirita, Mina do Chico Rei; c ed-veio superficial de quartzo-arsenopiritacarbonatos cortando dolomito, Antônio Pereira; Mina de Passagem: $e$-precipitações sobre parede da mina; $f$-veio de quartzo-arsenopirita-carbonato; $g$-precipitações sobre parede da mina 
do $\mathrm{Fe}$ e $\mathrm{O}$ a presença de As na goethita (Figs. 2 e 5).

Ocorrências de arsenopirita associada a carbonatos

ANTÔ-
NIO PEREIRA (MARIANA) No depósito aurífero de Antônio Pereira os veios com arsenopirita cortam mármores dolomíticos da Formação Gandarela. A superfície destes veios, especialmente

Tabela I - Principais minerais presentes nas rochas sulfetadas

\begin{tabular}{|c|c|c|}
\hline local & contexto geológico & minerais identificados por DRX \\
\hline Lages & $\begin{array}{l}\text { veios com quartzo e } \\
\text { arsenopirita }\end{array}$ & escorodita, quartzo, ilita, biotita \\
\hline Mina do Chico Rei & $\begin{array}{l}\text { veio com quartzo e } \\
\text { arsenopirita }\end{array}$ & quartzo, escorodita, goethita, hematita, ilita \\
\hline Antônio Pereira & $\begin{array}{l}\text { veios com quartzo, } \\
\text { arsenopirita, e carbonatos }\end{array}$ & $\begin{array}{l}\text { arsenopirita, ankerita, dolomita, calcita, Yukonita, Kolfanita, escorodita, krautita, } \\
\text { jarosewichita }\end{array}$ \\
\hline \multirow[t]{4}{*}{ Mina de Passagem } & veio com quartzo, arsenopirita & quartzo, arsenopirita, escorodita \\
\hline & $\begin{array}{l}\text { veio com quartzo, carbonatos } \\
\text { e arsenopirita, }\end{array}$ & $\begin{array}{l}\text { quartzo, arsenopirita, ankerita, dolomita, escorodita, sódio-farmacossiderita, } \\
\text { farmacossiderita, goethita, gipsita, bukoviskita, huntita }\end{array}$ \\
\hline & $\begin{array}{l}\text { turmalinitos (turmalinas, } \\
\text { arsenopirita, quartzo) }\end{array}$ & $\begin{array}{l}\text { quartzo, dravita, arsenopirita, biotita, anita, goetita, ilita, calcita, arsenolita, caulinita, } \\
\text { flogopita }\end{array}$ \\
\hline & $\begin{array}{l}\text { precipitações sobre as paredes } \\
\text { da mina }\end{array}$ & escorodita, jarosita, hidrônio-jarosita, kankita \\
\hline \multicolumn{3}{|c|}{ 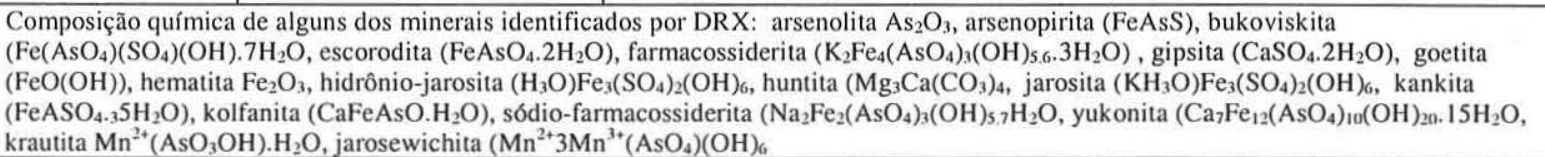 } \\
\hline
\end{tabular}
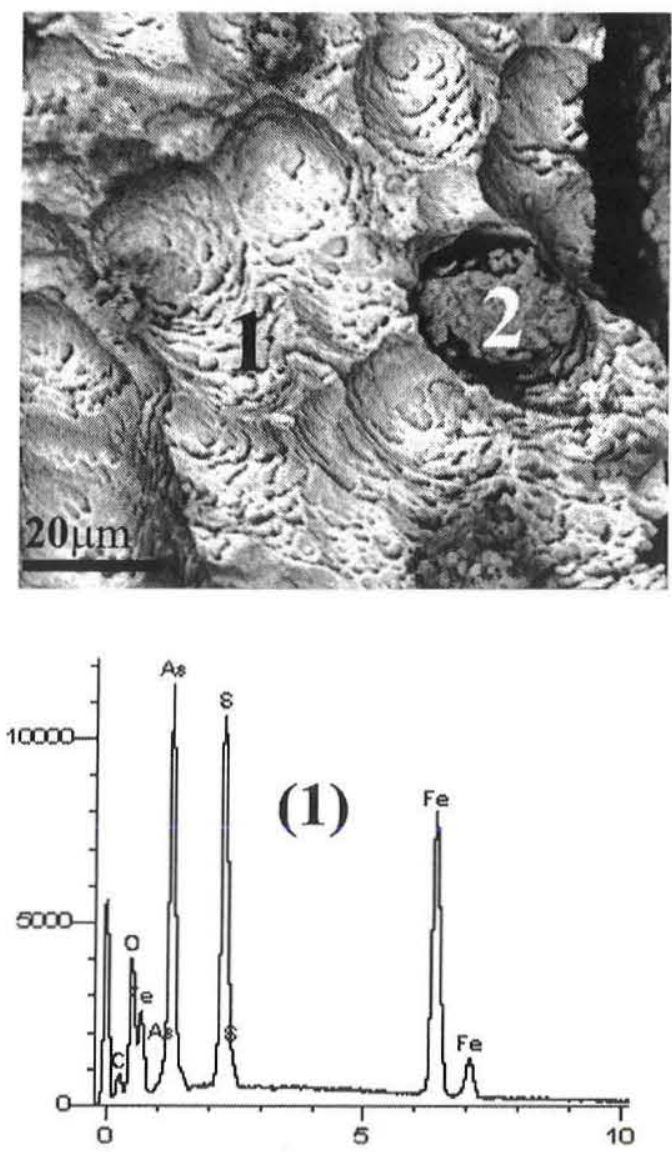

Figura 3 - Alvéolos de dissolução na arsenopirita (1) com grão de escorodita (2) precipitado no interior de um dos alvéolos. $\mathrm{Na}$ arsenopirita, sem camadas de oxidação aparentes, foi detectado O pela análise por EDS. Veio superficial de quartzo-arsenopirita, Lages.
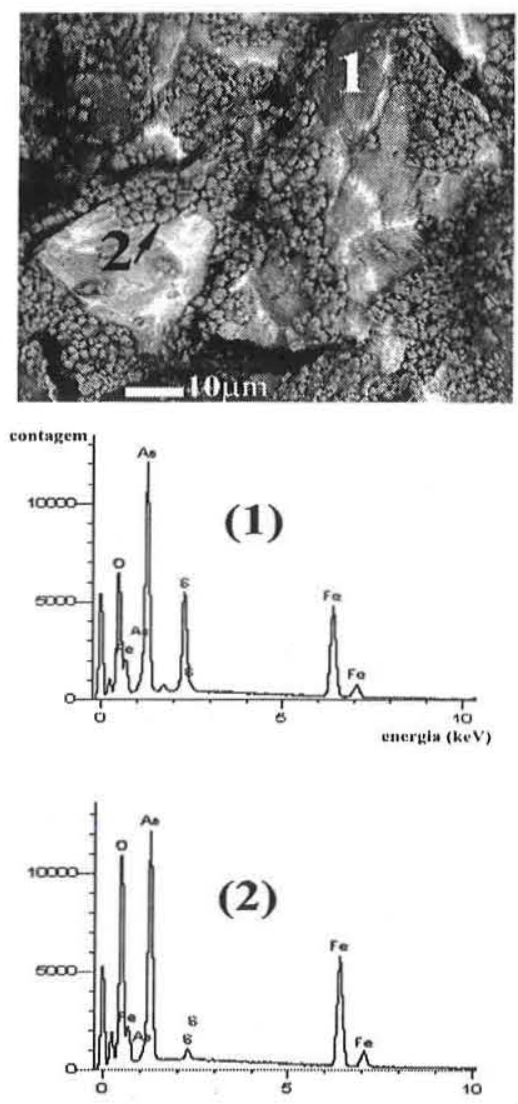

Figura 4 - Camada de arsenato de ferro hidratada (1), com gretas de dissecação, sobre arsenopirita (mineral branco sob as gretas) e grãos de escorodita (2) precipitados sobre a camada de arsenato de ferro e sobre outros minerais. A análise pelo EDS mostrou que a camada de arsenato de ferro possui mais $S$ que os grãos. Veio superficial de quartzo-arsenopirita, Lages. 
sobre as porções sulfetadas dos mesmos, estava recoberta por uma camada ocre pulverulenta. A minerais primários presentes nos veios são quartzo arsenopirita, ankerita, dolomita e calcita. Os minerais formados a partir da alteração da arsenopirita foram influenciados pelo ambiente geoquímico rico em $\mathrm{Ca}$, originando minerais secundários de arsênio com cálcio como a kolfanita e a yukonita, subordinadamente foram encontrados krautita, jarosewichita e a escorodita (Tabela 1).

O processo de oxidação da arsenopirita provocou o desenvolvimento de cavidades orientadas nos cristais; a análise da superfície da arsenopirita pelo EDS mostrou o enriquecimento da mesma em alguns pontos em $\mathrm{Ca}$ e $\mathrm{O}$ e o "empobrecimento" em $\mathrm{S}$. Recobrindo a arsenopirita existem camadas de minerais secundários, que também foram encontrados preenchendo espaços inter/ intragrãos da arsenopirita ou crescendo como cristais fibrosos (Fig.6). A composição dos minerais secundários que recobrem a arsenopirita, determinada pelo EDS, indicou a presença de As, $\mathrm{Fe}, \mathrm{Ca}$ e O. Outros minerais secundários encontrados foram: óxidos de $\mathrm{Fe}$ com $\mathrm{Ca}$, As e $\mathrm{Mn}$; carbonato de $\mathrm{Ca}$ e Fe com As, carbonato de $\mathrm{Ca}, \mathrm{Fe}$ e $\mathrm{Mg}$.
MINA DE PASSAGEM A presença de água na Mina de Passagem (MP), Pia Nova, em escorrimentos pelas paredes e gotejamentos do teto, ocorre de modo disseminado na parte superior da mina, o nível 120 . Com o aumento da profundidade, nos níveis 265 e 315, a água drena apenas através de fraturas e de veios. O nível da água é mantido artificialmente no nível 315 (cerca de $80 \mathrm{~m}$ abaixo da superfície, em relação a boca da mina) através de um duto lateral por onde o excesso de água escoa para o rio do Carmo.

No nível 120 as rochas estão intensamente intemperizadas constituindo, assim como na MCR, um horizonte saprolítico onde os sulfetos e o carbonato estão freqüentemente alterados. Neste nível, onde foram encontradas raízes de plantas, os espeleotemas carbonáticos e as precipitações de minerais sobre as paredes da mina são mais comuns que nos níveis mais profundos. Com o aumento da profundidade, nos níveis 265 e 315 , as rochas possuem em geral apenas uma camada de oxidação superficial, a exceção acontece nos locais onde há presença de água, quando a atuação do intemperismo sobre as rochas é mais intensa.
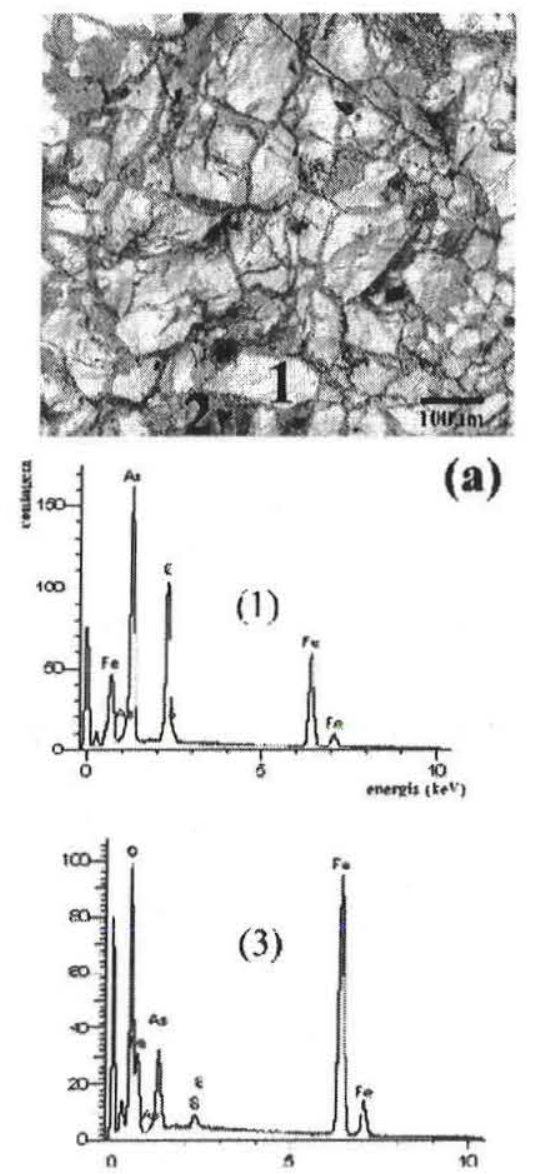

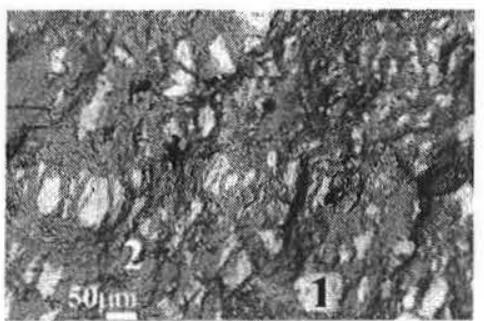

(b)
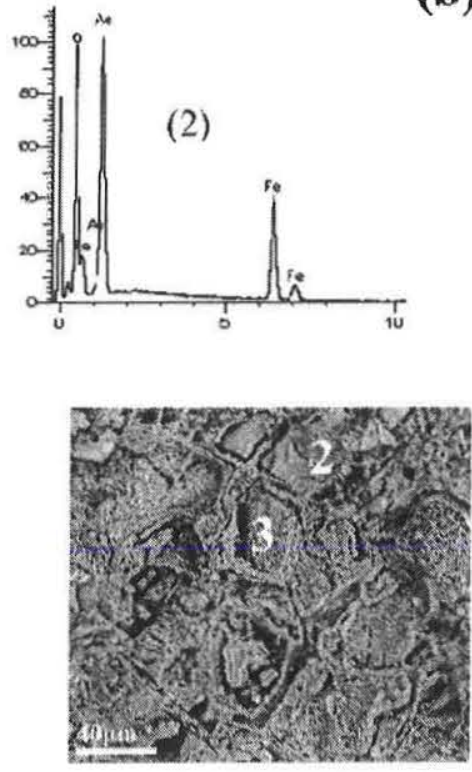

(c)

Figura 5 - Veio bandado de quartzo-arsenopirita, Mina do Chico Rei. No centro do veio(a) a substituição da arsenopirita (I) pela escododita (2) se dá através de bordas e fraturas dos cristais de arsenopirita, já na parte da amostra próxima à borda do veio (b) a arsenopirita (1) foi praticamente toda substituída pela escorodita (2). Notar o aspecto maciço da escorodita. Na superfície do veio (c) onde a arsenopirita foi oxidada quase completamente, a escorodita (2), sofreu um processo de dissolução incongruente, o que ocasionou a liberação de As e a formação de goethita (3) com As. Notar o aspecto maciço da escorodita e poroso do óxido de ferro. 

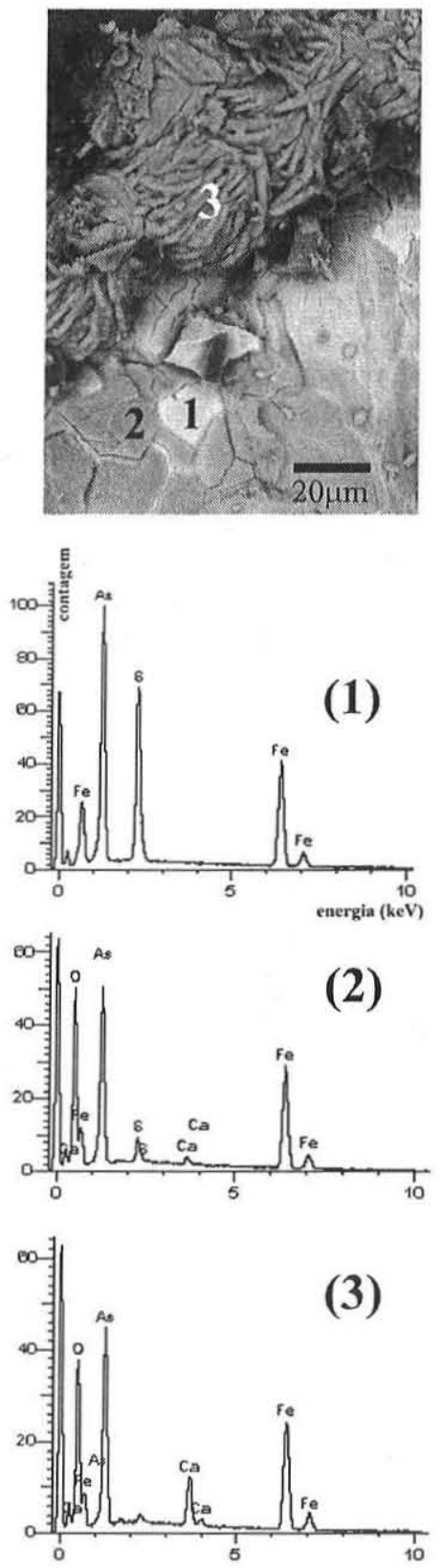

Figura 6 - Arsenopirita (1) coberta pelo arsenato de ferro (2) composto por FeAsO. $\mathrm{H}_{2} \mathrm{O}$, com traços de $\mathrm{Ca}, \mathrm{S}$. Sobre o arsenato de ferro houve a precipitação de cristais fibrosos (3) compostos por $\mathrm{FeCaAsO}$. Veio superficial de quartzo-carbonato-arsenopirita, Antônio Pereira.

Na MP a arsenopirita, e os minerais secundários de As, estão presentes em três associações mineralógicas distintas: (i) em veios de quartzo e arsenopirita; (ii) em turmalinitos, (iii) em veios de quartzo, carbonato e sulfeto. Além destas situações, os minerais secundários de As podem ser encontrados em precipitações sobre as paredes da mina. Os minerais secundários de As puderam ser identificados por DRX somente nas amostras mais intemperizadas, provenientes dos níveis superiores da mina, em função da massa do mineral na amostra necessário para a análise por DRX. Os minerais secundários de As encontrados foram: escorodita, kankita, sódio-farmacossiderita, farmacossiderita e arsenolita. Outros minerais primários e secundários que estavam presentes nas amostras foram: hidrônio-jarosita, jarosita, gipsita, huntita, goethita, calcita, dolomita. Na tabela 1 os minerais secundários e primários estão organizados segundo as situações geológicas em que ocorrem.

Em rochas da parte superior da mina o intemperismo promoveu a oxidação completa da arsenopirita e o intemperismo de outros minerais em vários locais. Os cristais de arsenopirita apresentaram feições de dissolução como alvéolos e franjas, cuja análise pelo EDS determinou a presença de $\mathrm{Fe}, \mathrm{As}, \mathrm{Se} \mathrm{O}(\mathrm{Ca})$. As camadas de minerais secundários constituídas por $\mathrm{FeAsO}(\mathrm{Ca}, \mathrm{S})$ foram encontradas associadas à arsenopirita em diversas situações: recobrindo os grãos (Fig.7), no contato intergranular, em fraturas no interior dos grãos e em poros intergranulares. Nos poros secundários foram observados minerais precipitados sobre as. superfícies de minerais primários e secundários tais como: (i) gipsita e oxido de ferro precipitados sobre arsenato de ferro e este último sobre a arsenopirita; (ii) dolomita secundária sobre arsenato de ferro (Fig.8).

Nos níveis mais profundos da MP a oxidação da arsenopirita ocorreu apenas na superfície dos cristais, sendo detectada através do MEV. Sobre as superfícies dos cristais de arsenopirita, em veios constituídos por quartzo-carbonato-arsenopirita e nos turmalinitos, também foram observadas as placas constituídas por $\mathrm{FeAs}(\mathrm{Ca}) \mathrm{O}$. Nas amostras dos veios constituídos por quartzo-carbonato-arsenopirita foram encontrados gipsita (Fig. 9) e, mais raramente, um óxido formado por $\mathrm{MgAsO}$ recobrindo a camada de arsenato de ferro. A determinação da composição superficial da arsenopirita pelo EDS indicou, além de $\mathrm{Fe}$, as e $\mathrm{S}$ a presença de $\mathrm{O}$.

Nos turmalinitos os minerais secundários encontrados foram escorodita, arsenolita e goethita. No MEV observou-se a substituição da arsenopirita apenas por pseudomorfos compostos por Fe, As, O com Ca e S (Fig.10).

Em várias paredes da mina, sobre os veios e em pontos das rochas por onde percola/goteja água, houve a precipitação de diversos minerais como escorodita, kankita, jarosita e hidrôniojarosita (Tabela 1 e Fig. 2). As precipitações também deram origem a espeleotemas compostos por calcita, aragonita, dolomita e goethita.

Hidrogeoquímica das águas das minas do Chico Rei e Passagem Na MCR, em Ouro Preto, foram coletadas uma amostra de água (OP1) que escorria a partir de um veio mineralizado, e duas amostras de água de minas próximas e localizadas topograficamente acima da MCR, nas minas Quartzito (OP2) e Lages (OP3).

Em Ouro Preto, na MCR a água possui $\mathrm{pH} 7$ e o Eh de 330 $\mathrm{mV}$. Os íons com maiores concentrações são: $\mathrm{Ca}, \mathrm{Mg}$ e o $\mathrm{SO}_{4}^{2-}$ (Tabela 2). Dos elementos traço analisados, detectou-se apenas o As com a concentração de $260 \mu \mathrm{g} / \mathrm{L}$. A determinação das espécies inorgânicas de As forneceu a seguinte distribuição: $\mathrm{As}^{5+}=248$ $\mu \mathrm{g} / \mathrm{L} \mathrm{e} \mathrm{As}^{3+}=12 \mu \mathrm{g} / \mathrm{L}$.

Na MP foram coletadas amostras de água de vários níveis provenientes de diferentes situações como gotejamentos do teto (em locais com e sem espeleotemas), percolações através de veios mineralizados e também no lago da parte inundada da mina. Esta abordagem permitiu a identificação de águas com diferentes composições químicas.

As amostras de água apresentaram $\mathrm{pH}$ entre neutro a levemente alcalino, com valores entre 7 e 8 , natureza oxidante com o Eh entre $360-420 \mathrm{mV}$ e a concentração de oxigênio dissolvido 

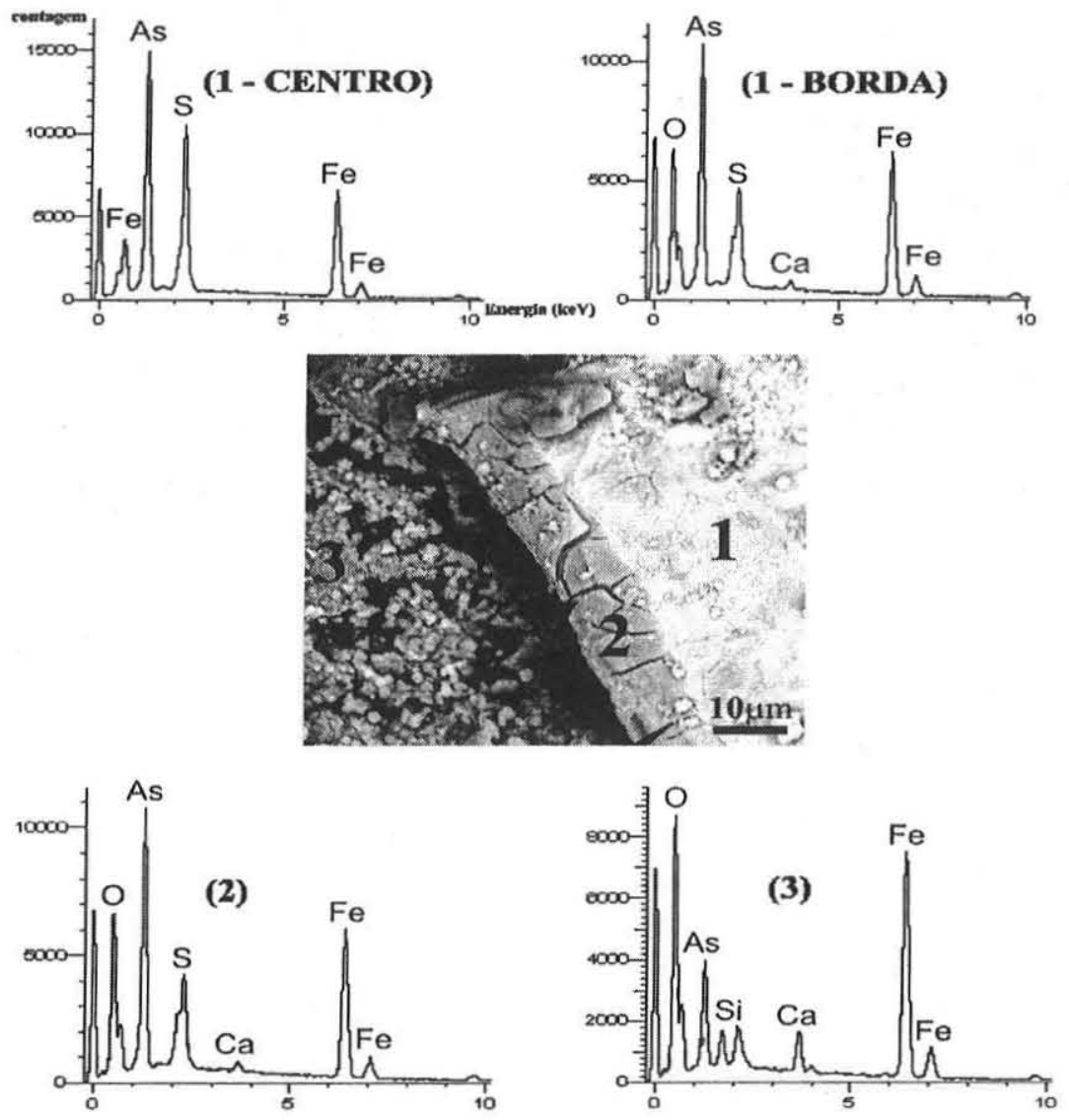

Figura 7 - Contato contínuo e irregular entre arsenopirita (1) e camada de arsenato de ferro apresentando gretas de contração (2). Na borda do cristal de arsenopirita nota-se a presença de $\mathrm{O}$ e Ca. A composição da camada de arsenato de ferro é semelhante à da borda da arsenopirita. Nos grânulos precipitados ao lado da arsenopirita (3) o S está ausente e o $\mathrm{O}$ e o Ca possuem maiores concentrações relativas. Veio de quartzo-carbonato-arsenopirita, Mina de Passagem, N120.

entre 4 e 6,5 mg/L. Os principais íons encontrados nas amostras foram: $\mathrm{Ca}, \mathrm{Mg} ; \mathrm{HCO}_{3}$ e o $\mathrm{SO}_{4}^{2 \cdot}$ são os anions predominantes nas amostras com menores (PM 1, 2 e 4) e maiores (PM 3 e 5) concentrações de As, respectivamente (Tabela 2). Na MP dos elementos traço apenas o As apresentou concentrações mensuráveis. As amostras com menores teores, de 1 a $20 \mu \mathrm{g} / \mathrm{L}$, foram coletadas a partir de gotejamentos do teto da mina, numa unidade estratigráfica acima das rochas mineralizadas (amostras PM 1,2 e 4; Tabela 2). As amostras com as maiores concentrações de As, com valores de 1760 e $2980 \mu \mathrm{g} / \mathrm{L}$, foram coletadas de percolações através de veios mineralizados e no lago da parte inundada da mina (amostras PM 3 e 5; Tabela 2). O As ${ }^{5+}$ é a espécie inorgânica predominante; nas amostras PM 2, 3 e 4 foram obtidas concentrações de 1701, 2894 e $3 \mu \mathrm{g} \mathrm{L}$ L $^{-1}$ respectivamente (Tabela 2), já o $\mathrm{As}^{3+}$ está presente nas amostras de água em concentrações inferiores a $5 \%$ do As Total $_{\text {(Tabela } 2) .}$

DISCUSSÕES O intemperismo sobre as rochas sulfetadas e os minerais secundários de As formados As características geoquímicas dos veios mineralizados e de suas rochas encaixantes, independente se localizados em superfície ou subsuperfície, foram responsáveis pelos minerais secundários de arsênio precipitados. Os minerais secundários de As (escorodita, kankita e bukoviskita), e as precipitações com baixa cristalinidade (arsenatos de ferro) foram os únicos compostos químicos encontrados nos ambientes geoquímicos pobres em $\mathrm{Ca}$, como os veios de quartzo e arsenopirita das Lages, da MCR, ou que não tiveram o acesso de soluções alcalinas e ricas em $\mathrm{Ca}$ como os veios de quartzo e arsenopirita e os turmalinitos da MP. Por outro lado, nos veios encaixados nas rochas carbonáticas em Antônio Pereira, foram encontrados apenas minerais secundários de $\mathrm{As}, \mathrm{Fe} e \mathrm{Ca}$, yukonita e kolfanita, e minerais de Mn, jarosewichita e krautita. Na MP apesar de não terem sido encontrados minerais secundários de As e $\mathrm{Ca}$, os arsenatos de ferro e os óxidos de Fe presentes nos veios de quartzo-carbonato-sulfeto ou precipitados sobre turmalinitos sempre apresentaram $\mathrm{Ca}$ em sua composição. A ausência de minerais de $\mathrm{Fe}$, As e Ca na MP pode estar relacionada a uma disponibilidade menor de $\mathrm{Ca}$ em relação aos veios sulfetados de Antônio Pereira que cortam rochas dolomíticas.

Tanto em Antônio Pereira como na MP, o exame por DRX de porções concentradas de sulfeto oxidado das mineralizações com carbonatos apresentaram pequenas quantidades de minerais secundários de As. Por outro lado, a observação destas amostras no MEV indicou que estas porções com sulfetos oxidados são compostas por $\mathrm{Fe}, \mathrm{As}, \mathrm{O}$ e Ca, o que sugere que os minerais secundários de As nestas amostras possuem baixa cristalinidade. 


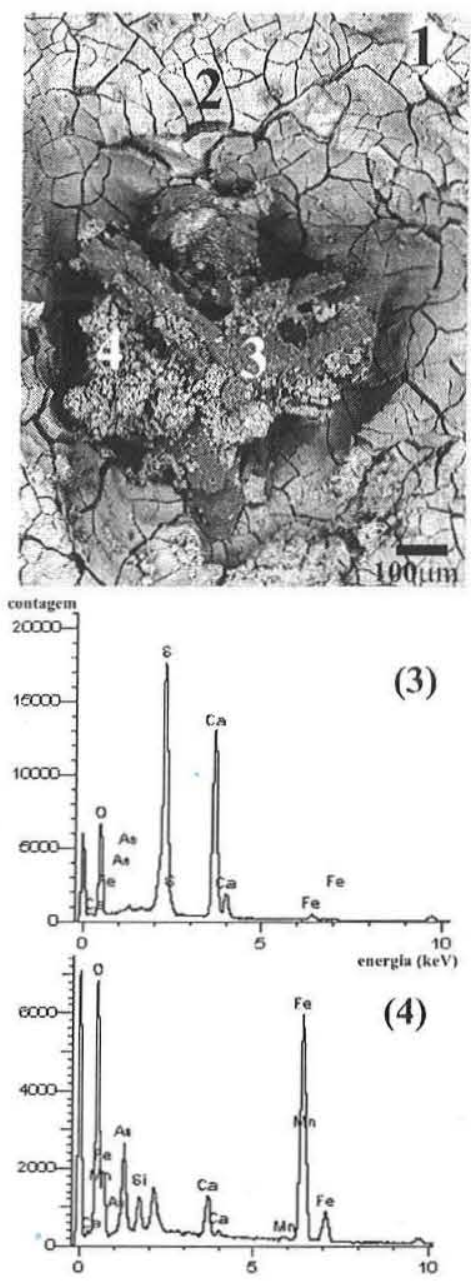

Figura 8 - Arsenopirita (1) coberta por arsenato de ferro (2). $\mathrm{Na}$ porosidade secundária da rocha houve a precipitação de gipsita (3) e óxido de ferro com As e Ca (4). Veio de quartzo-carbonatoarsenopirita, Mina de Passagem, N120.

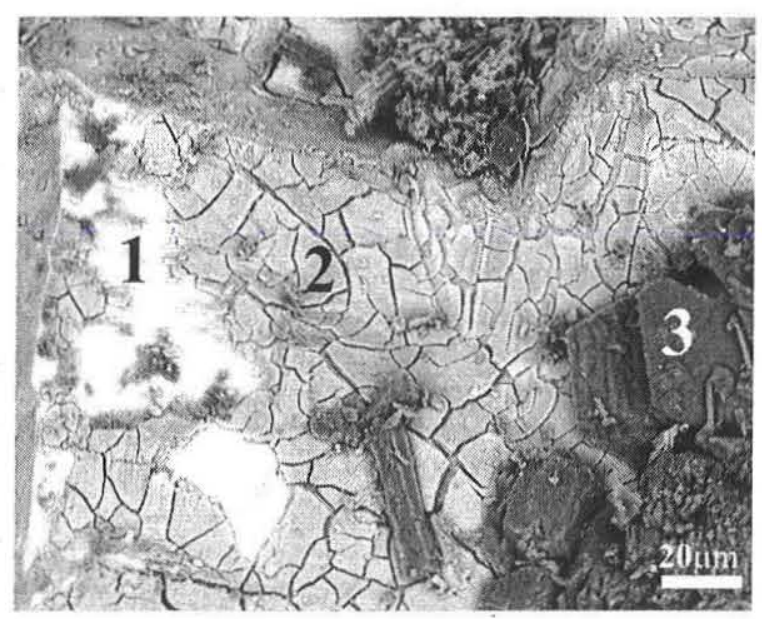

Figura 9 - Cristal de arsenopirita (1) recoberto por arsernato de ferro (2) e gipsita (3). Veio de quartzo-carbonato-arsenopirita, Mina de Passagem, N315.
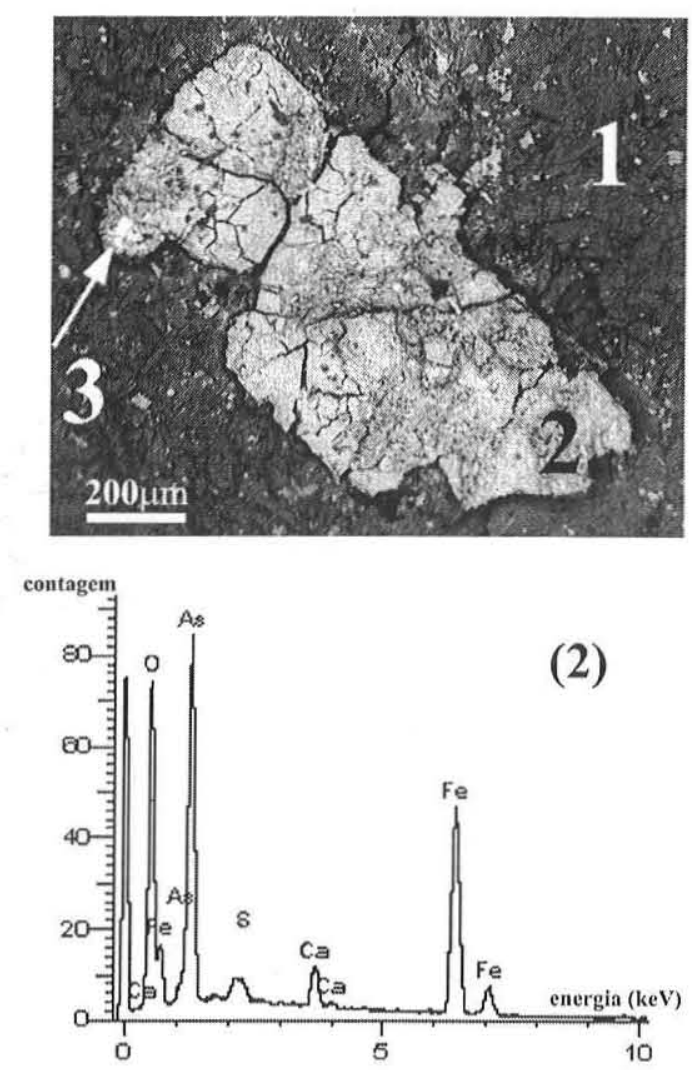

Figura 10 - Cristais de turmalina (1) intactos ao lado do pseudomorfo (FeAsO com Ca e S) de arsenopirita (2) e restos de arsenopirita (3). Turmalinito, MP, N265.

Tabela 2 - Composição química das águas das minas

\begin{tabular}{lrrrrrrrr}
\hline & \multicolumn{3}{c}{$\mathrm{PM}$} & & \multicolumn{3}{c}{ OP } \\
\hline & 1 & 2 & 3 & 4 & 5 & 1 & 2 & 3 \\
\hline $\mathrm{pH}$ & 7 & 8 & 7 & 7 & 8 & 7 & 7 & 6 \\
$\mathrm{Eh}(\mathrm{mV})$ & 380 & 370 & 360 & 420 & 380 & 430 & 481 & 330 \\
$\mathrm{Ca}$ & 47 & 51 & 21 & 9 & 24 & 6 & 1 & 1 \\
$\mathrm{Mg}$ & 30 & 32 & 14 & 5,4 & 14 & 4 & 0,4 & 1 \\
$\mathrm{Na}$ & 3 & 4 & 1 & 1 & 6 & 1 & 1 & 0,2 \\
$\mathrm{~K}$ & 1 & 6 & 1 & 1 & 3 & 1 & 0,4 & 0,2 \\
$\mathrm{HCO}$ & 234 & 381 & 74 & 56 & 94 & 12 & 8 & 12 \\
$\mathrm{Cl}_{3}$ & 4 & 3 & 1 & 3 & 5 & 3 & 1 & 1 \\
$\mathrm{SO}_{4}$ & 10 & 10 & 38 & 3 & 42 & 19 & 2 & 1 \\
$\mathrm{As}_{\text {Total }}$ & 4 & 20 & 2980 & 1 & 1760 & 260 & 24 & 12 \\
$\mathrm{As}^{3+}$ & 1 & - & 86 & 0 & 59 & 12 & - & - \\
$\mathrm{As}^{5+}$ & 3 & - & 2894 & - & 1701 & 248 & - & - \\
\hline & & & & & & & &
\end{tabular}

Concentrações em mg/L, exceto para o As em $\mu \mathrm{g} / \mathrm{L}$. Legenda: Mina de Passagem - PM: 1 - N120 - goteira do teto com estalactite, 2-N175 - goteira do teto com estalactite; 3- N265 - água gotejante do veio mineralizado; 4- N265 - água gotejante do teto; 5-N365 Lago ; OP: 1-Mina do Chico Rei, 2-Mina Quartzito; 3-Mina Lages 
Oxidação da arsenopirita Sob condições naturais de intemperismo, nos cristais de arsenopirita sem sinais aparentes de oxidação foi detectada a presença de $\mathrm{O}$ e a perda de $\mathrm{S}$ na superfície destes cristais analisados por EDS. Supõe-se que esta situação marque o início do processo de oxidação. A continuidade e a intensificação da oxidação da arsenopirita deu origem à formação de uma camada oxidada com espessura variável constituída por arsenato de ferro nas rochas sem carbonato e por arsenato de Fe$\mathrm{Ca}$ nas rochas que contém carbonato. As camadas de oxidação ocorrem (i) envolvendo os cristais, (ii) no contato intergranular e (iii) em fraturas internas dos cristais.

$\mathrm{Na}$ formação experimental da camada de oxidação sobre a arsenopirita, a difusão de íons através da rede cristalina da arsenopirita e da própria camada de oxidação tem sido apontada como responsável pela mobilidade dos íons $\mathrm{Fe}, \mathrm{As}, \mathrm{S}, \mathrm{O}$ e $\mathrm{OH}$ (Richardson \& Vaughan 1989; Nesbitt et al.,1995; McGuire et al.,2001a e 2001b; Fernandez et al.,1995).

Richardson \& Vaughan (1989) e Nesbitt et al.(1995) observaram que na oxidação inorgânica da arsenopirita houve o desenvolvimento de uma camada de oxidação sobre os cristais com espessura de 10-50 $\AA$, onde foram detectadas a perda de $\mathrm{S}$, a concentração de óxidos $\mathrm{Fe}^{3+}$ e oxi-hidroxianions de $\mathrm{As}^{3+}$ e $\mathrm{As}^{5+}$. McGuire et al. (2001a e 200lb) constataram que o S, na forma elementar, alcança a superfície por difusão através da camada de oxidação e precipitando-se aleatoriamente sobre a mesma. Nesbitt et al.(1995) e Fernandez et al.(1995) averiguaram que os oxianions de $\mathrm{As}$ e $\mathrm{Fe}^{3+}$ acumulados na camada de oxidação da arsenopirita seriam solubilizados pelas soluções diluídas dos experimentos. A existência de $\mathrm{As}^{3+}$ e nas amostras de água das minas do Chico Rei e de Passagem (Tabela 2) é indicativo da solubilização do $\mathrm{As}^{3+}$ do $\mathrm{As}^{5+}$ acumulados na superfície oxidada da arsenopirita, o sendo que o $\mathrm{As}^{5+}$ pode ser ainda originado a partir da dissolução da camada oxidada.

Assim como nos experimentos, a difusão de íons através da camada oxidada sobre a arsenopirita deve ter ocorrido, viabilizando a continuidade da oxidação destes cristais recobertos. Através desta camada oxidada haveria o aporte de $\mathrm{O}$ e $\mathrm{H}_{2} \mathrm{O}$ e a remoção de $\mathrm{Fe}$, As e S. Em amostras da MP (Figs. 7, 8, 9 el0), a formação de arsenatos de $\mathrm{Ca}$ ou a incorporação de $\mathrm{Ca}$ na camada de oxidação da arsenopirita das rochas de Antônio Pereira e da MP, ricas em carbonatos, indica que o Ca em solução (vide amostras da MP, Tabela 2) também participou do processo de difusão e formação da camada de oxidação. A ausência de $\mathrm{S}$ na superfície das camadas de oxidação pode estar relacionada com a solubilização do mesmo e também com a precipitação de outros minerais como a gipsita, conforme foi observado na MP (Figs. 8 e 9).

Em conjunto com a difusão de íons, as bactérias também devem ter tido participação na formação das espessas camadas de oxidação encontradas sobre a arsenopirita. As bactérias participariam acelerando o processo de oxidação em até 5 vezes, conforme verificado por McGuire et al. (2001a) em relação à oxidação abiótica da arsenopirita. As camadas de arsenato de ferro e arsenato de Fe-Ca possuem espessuras em torno de $10 \mu \mathrm{m}$ (Fig. 7), elas são cerca de 10000 mais espessas do que as camadas de oxidação encontradas nos experimentos de oxidação inorgânica conduzidos por Richardson \& Vaughan (1989) e Nesbitt et al.(1995), possivelmente devido ao tempo de duração ou à ausência de bactérias nos experimentos.

Os aspectos texturais da camada de arsenato de ferro e da superfície oxidada da arsenopirita nas diferentes ocorrências aqui estudadas são semelhantes àqueles observadas por Fernandez et al. (1995), que utilizou bactérias Thiobacillus ferrooxidans na oxidação experimental da arsenopirita. Em seu experimento Fernandez et al. (1995) observou que houve a formação de uma camada de arsenato de ferro sobre a arsenopirita em apenas 11 dias, e que a cobertura das bactérias pela camada de arsenato de ferro seria um fator de inibição da continuidade da oxidação. Entretanto, nas amostras aqui estudadas, as camadas sobre os cristais de arsenopirita não foram agentes inibidores da oxidação, que prosseguiu independente das coberturas sobre os cristais, conforme pode ser observado no avanço da fronteira de oxidação sobre a arsenopirita e mesmo nas substituições isomórficas (Figs. 7 e 10). A cobertura dos cristais pode inclusive favorecer a continuidade da oxidação num meio neutro por criar um nanoambiente ácido, conforme observado por Mielke et al. (2003).

A oxidação da arsenopirita representa portanto um processo de dissolução incongruente, no sentido de Stumm (1992), onde é formado o arsenato de ferro, ou arsenato de $\mathrm{Fe}-\mathrm{Ca}$, sobre a arsenopirita ao mesmo tempo em que parte do As e do Fe e todo o S são solubilizados. Os íons solubilizados podem ser transportados a distancias maiores, dando origem às precipitações encontradas nas paredes da MP. O aumento da concentração dos íons deve ocorrer pela perda de água por evaporação, levando a solução a se tornar saturada ou mesmo supersaturada. Ao atingir o ponto de supersaturação (Stumm \& Morgan 1996) haveria a precipitação dos grãos de arsenato de ferro sobre a camada oxidada da arsenopirita e sobre outros minerais da amostra (Fig. 4) dando origem a duas gerações de arsenato de ferro.

Em termos termodinâmicos, a escorodita é mais estável que o arsenato de ferro com baixa cristalinidade, por possuir menor energia livre de formação, $-1280 \mathrm{~kJ} / \mathrm{mol}$ e $-1267 \mathrm{~kJ} / \mathrm{mol}$ respectivamente. Pode-se esperar que o arsenato de ferro com baixa cristalinidade se transforme em escorodita com o tempo (Welham et al. 2000) caso as condições físico-químicas do meio sejam favoráveis, i.e., em especial que o $\mathrm{pH}$ seja menor que 4. A presença de minerais secundários de As com elevada cristalinidade, avaliada através da DRX, foi maior nos veios das Lages e da MCR do que nos veios da MP e Antônio Pereira. O ambiente com menor $\mathrm{pH}$, como os veios das Lages e da MCR, é mais favorável à formação/transformação de minerais secundários de As com maior cristalinidade (Dove \& Rimsdidt 1985; Krause \& Ettel 1988) do que aqueles com $\mathrm{pH}$ mais elevado, encontrados na MP e em Antônio Pereira, que tem capacidade de neutralização da acidez através da dissolução dos carbonatos presentes nas rochas e veios.

Ambientes geoquímicos em subsuperfície As rochas carbonáticas da MP favorecem a uma condição hidrogeoquímica alcalina. Apesar disto, soluções ácidas com metais solubilizados foram encontradas percolando veios de quartzo e arsenopirita e turmalinitos. Nos locais de percolação das soluções ácidas em que houve a supersaturação dos íons dissolvidos, possivelmente pela evaporação da água, haviam minerais precipitados sobre as paredes da mina: escorodita e kankita e em outro local jarosita e hidrônio-jarosita. No diagrama de Eh-pH (Fig. 11) observa-se que a escorodita $\left(\mathrm{FeAsO}_{4} \cdot 2 \mathrm{H}_{2} \mathrm{O}\right)$ é estável em soluções com $\mathrm{pH}<6$ enquanto que a jarosita é estável a $\mathrm{pH}<2$. Com maior distribuição na MP, as soluções alcalinas com $\mathrm{pH} \approx 7-8$ (Tabela 2), gotejam com abundância do teto ou escorrem pelas paredes a partir de fraturas, havendo em muitos locais a precipitação de espeleotemas de carbonatos (Tabela 2). Estas fontes pontuais de soluções aquosas ácidas e alcalinas ocorrem muitas vezes a poucos metros de distância entre si, nos locais com maior umidade da mina. 


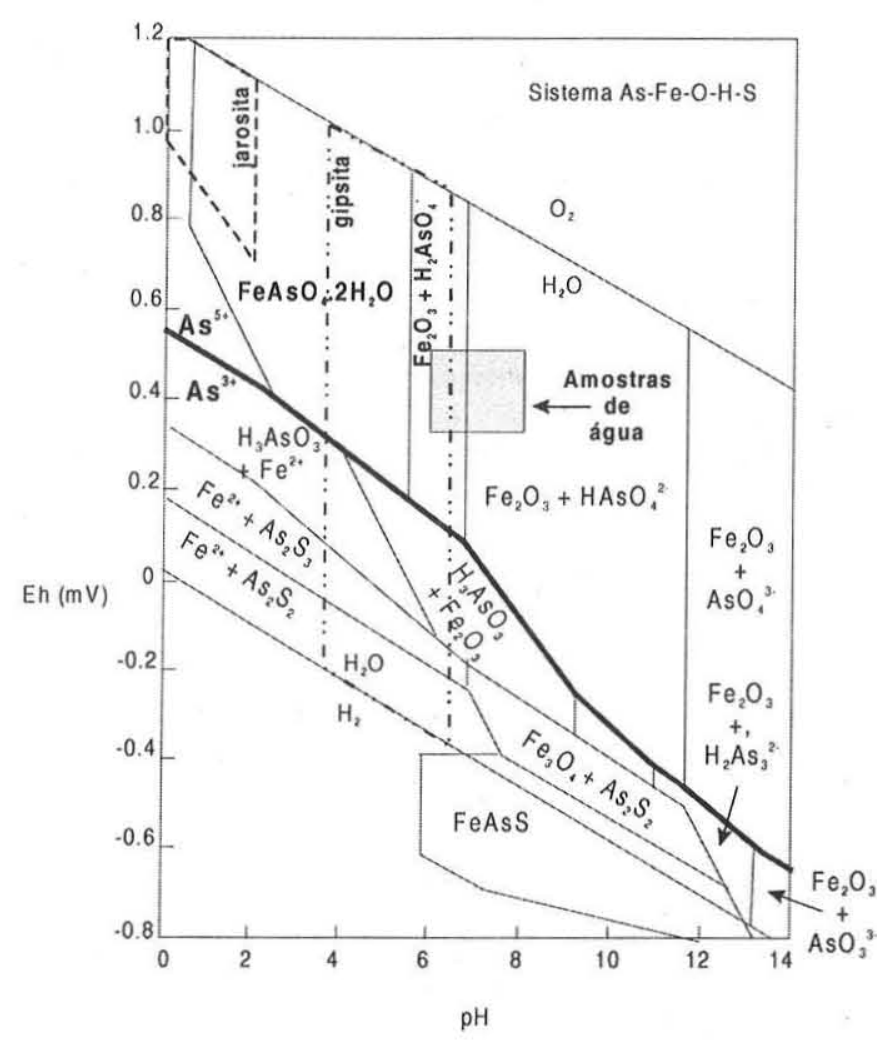

Figura 11 - Diagrama de Eh-pH para o sistema As-Fe-H-S (modificado de Vink 1996), onde foram plotados os campos de estabilidade da jarosita (Bigham \& Nordstrom 2000) e da gipsita (Brookins 1988). Notar a linha cheia que divide os campos de estabilidade das espécies de $\mathrm{As}^{3+}$ e $\mathrm{As}^{5+}$ e a região sombreada definida pelas amostras de água das minas, situado no campo de estabilidade das espécies de $\mathrm{As}^{5+}$.

A heterogeneidade da composição química das águas da MP pode ser decorrente de (i) razões água-rocha e velocidade de percolação diferentes: nas zonas densamente fraturadas ou com grande porosidade, ambas elevadas se comparadas com os veios, há a diluição dos metais dissolvidos, enquanto que nos veios, com percolação mais lenta e menor volume de água há a saturação dos íons em solução e ocorre a precipitação de minerais secundários; (ii) locais diferentes de percolação das águas, uma vez que as rochas possuem uma distribuição heterogênea dos minerais, estando os sulfetos concentrados em veios e turmalinitos, onde haveria a possibilidade da geração de soluções com maiores concentrações de metais e As e com pH menores devido à oxidação dos sulfetos.

A heterogeneidade da composição química das soluções também foi observada indiretamente num mesmo local através dos minerais secundários existentes, neste caso a variação hidrogeoquímica seria temporal. Num microporo da MP, foram identificados arsenato de ferro, gipsita e óxido de ferro (Fig. 8). A coexistência destes minerais secundários no microporo implica numa condição de metaestabilidade do arsenato de ferro (Fig. 11). A principal mudança do meio deve ter ocorrido em relação ao $\mathrm{pH}$, que teria aumentado de modo gradativo. Inicialmente o $\mathrm{pH}$ deveria ser menor que 4 para que houvesse a formação do arsenato de ferro, em decorrência da oxidação da arsnopirita, pois acima deste valor já teria início a dissolução incongruente do arsenato de ferro dando origem à goethita (Welham et al. 2000). Com a elevação do pH haveria então condições para a cristalização da gipsita e do óxido de ferro, decorrente da referida dissolução incongruente do arsenato de ferro.

$\mathrm{O}$ aumento do $\mathrm{pH}$ poderia estar relacionado à variação do volume de água nos poros devido ao regime pluviométrico vigente, neste caso no aumento do volume e da circulação de solução do poro, tornando a solução menos saturada. Outra possibilidade seria decorrente do recobrimento da arsenopirita pela camada de arsenato de ferro, que apesar de não impedir, poderia provocar o retardamento da oxidação da arsenopirita e conseqüentemente da produção de acidez. Nestas circunstâncias a interação água-rocha teria resultado na elevação do $\mathrm{pH}$ das soluções nos poros, proporcionando a seqüência de precipitação de minerais: gipsita e oxido de ferro e a dissolução do arsenato de ferro.

Liberação e retenção de As A liberação do As a partir da arsenopirita e sua retenção via precipitação de minerais secundários de As e adsorção em outros minerais acontece em várias etapas e de modo distinto em superfície e subsuperfície.

A remoção, ou inexistência, do solo que recobria os veios em superfície possibilitou a exposição do seu produto de intemperismo, e como não há solo para proteger o material oxidado na superfície dos veios, ocorre a erosão e a solubilização dos minerais secundários de As pelas águas pluviais, que carreiam o As para o solo, o aqüífero e os rios. Entretanto os minerais secundários de As formados apresentam comportamentos distintos: a escorodita é o mineral secundário de As mais estável, seguida do arsenato de ferro ou arsenato de ferro e cálcio com baixo grau de cristalinidade. Segundo Welham et al. (2000), o arsenato de ferro com baixa cristalinidade é cerca de 190 vezes mais solúvel que a escorodita. Isto implica que, em superfície, os veios das Lages tem maior capacidade de retenção de As, pois predomina a escorodita sobre $\mathrm{o}$ arsenato de ferro, do que os veios carbonatados de Antônio Pereira, onde os arsenatos de ferro e cálcio com baixo grau de cristalinidade são predominantes. Esta facilidade de erosão acelera a oxidação da arsenopirita por remover os minerais secundários de As e expor sua superfície à oxidação.

Em subsuperfície, num ambiente com umidade mais constante, porém com fluxo mais lento de água e protegido da chuva, do sol e da erosão, a oxidação da arsenopirita resultou na cristalização de escorodita nos veios com quartzo e arsenopirita (MCR e Passagem) e de arsenato de ferro de baixa cristalinidade, contendo cálcio, nos veios carbonatados (MP).

A razão entre as densidades da escorodita e da arsenopirita $\left(R_{d}=2\right)$ indica que na substituição completa de um cristal de arsenopirita pela escorodita é necessário mais que o dobro do volume ocupado pela arsenopirita para o cristal de escorodita. Como em muitas amostras observa-se que não há o espaço necessário para que isto ocorra, a solubilização de parte do As e do $\mathrm{Fe}$ se faz necessária. Na substituição da arsenopirita por escorodita em veios com baixa porosidade, como na MCR, a falta de espaço físico para a formação de escorodita sugere que houve a necessidade do transporte em solução de cerca de metade do As proveniente da oxidação da arsenopirita.

$\mathrm{O}$ aumento do $\mathrm{pH}$, observado nas minas de Passagem e Chico Rei a partir dos minerais secundários precipitados e de suas transformações, promove a liberação de As a partir dissolução incongruente da escorodita, que tem como produto o As solubilizado e a goethita, que contém As. O transporte e a precipitação do arsenato de ferro/escorodita foi observado em algumas amostras e sobre 
veios na parede da mina a partir de soluções saturadas. Os fatores que retardam a solubilização do As seriam a lenta percolação da água, que controlaria a dissolução do arsenato de ferro, e a precipitação de goethita com As. Porém havendo a solubilização da camada de arsenato de ferro a superfície da arsenopirita ficaria novamente exposta à oxidação mais rápida, iniciando novamente o ciclo. A dissolução incongruente da escorodita originando a goetita só foi observada diretamente nos locais com baixa circulação de água das minas da Passagem e do Chico Rei.

CONCLUSÕES A paragênese mineral, o ambiente de oxidação (superficial ou sub-superficial), o volume de água disponível e sua renovação foram fatores decisivos na oxidação da arsenopirita, nos minerais secundários formados e no As solubilizado na água subterrânea.

A oxidação da arsenopirita em rochas sem carbonato (Lages e MCR) levou a formação de escorodita. Em superfície a oxidação foi mais intensa devido à ação intempérica sobre os veios, favorecida pela remoção da camada de oxidação que recobre os veios na época das chuvas. Em subsuperfície, com um regime mais restrito de circulação de águas, houve a substituição muitas vezes completa da arsenopirita pela escorodita. A dissolução incongruente da escorodita deu origem a goethita rica em As.

Em rochas e veios com carbonatos (Antônio Pereira, MP) os minerais secundários de As possuíam $\mathrm{Ca}$ como constituinte (yukonita, kolfanita, wallkilldellita) ou como impureza. O pH alcalino do ambiente dificultou a formação de escorodita, levando à formação de arsenatos de ferro com baixa cristalinidade, tendo $\mathrm{Ca}$ e $\mathrm{S}$ em menores quantidades. $\mathrm{O}$ arsenato de ferro forma camadas hidratadas que recobrem a maioria dos cristais de arsenopirita. Em subsuperfície houve ainda a precipitação de gipsita.

A presença de $\mathrm{As}^{3+} \mathrm{e} \mathrm{SO}_{4}^{2 \cdot}$ nas águas das minas do Chico Rei e Passagem é um indício da continuidade da oxidação da arsenopirita, apesar das coberturas de minerais secundários de As sobre a maioria dos cristais de arsenopirita. Entretanto o $\mathrm{As}^{5+}$, a principal espécie de As nas águas das minas com pelo menos $95 \%$ da concentração total, deve ser originário da dissolução total, ou incongruente, do arsenato de ferro com baixa cristalinidade na MP e da escorodita na MCR. O sulfato poderia vir também da dissolução da gipsita.

A liberação do As para as águas superficiais e subterrâneas ocorre por etapas: (i) a partir da oxidação da arsenopirita o As pode ser solubilizado e também participar da formação de arsenato de ferro ou escorodita; (ii) da dissolução total ou incongruente dos minerais secundários de As haveria a retenção do As como impureza ou adsorvido em óxido de ferro e também haveria a solubilização do As não retido. A presença de carbonatos nas mineralizações sulfetadas neutraliza a drenagem ácida, formada a partir da oxidação dos sulfetos, e favorece a retenção de metais como $\mathrm{Cu}, \mathrm{Cd}, \mathrm{Pb}$ e Zn, via co-precipitação ou adsorção em óxidos de ferro. Entretanto, no caso do As, o pH neutro a alcalino induz a liberação do As em solução através da dissolução de minerais secundários de As. Deste modo, as mineralizações ou rochas que contêm minerais de arsênio e carbonatos são as que liberam As dissolvido mais facilmente para as águas superficiais e subterrâneas, proporcionando um incremento em sua mobilidade em ambiente superficial.

Agradecimentos À FAPESP (processos 97/14446-6 e 96/78399), aos srs. Walter Rodrigues e Roberto Rodrigues pelo acesso e apoio à realização da pesquisa na mina da Passagem, ao Teinha $\mathrm{e}$ ao Eng. Geólogo José A. Cavalcanti pelo acompanhamento nos trabalhos de campo. Aos revisores da RBG pelas sugestões ao manuscrito.

\section{Referências}

Alpers C.N., Blowes D.W., Nordstron D.K., Jambor J.L. 1994. Secondary minerals and acid mine-water chemistry. In: J.L. Jambor, D.W. Blowes (eds.) The environmental geochemistry of sulfide mine-wastes. Mineralogical Association of Canada, Short course handbook, 22:247-270.

Armienta M.A., Villaseñor G., Rodriguez R., Ongley L.K., Mango H. 2001. The role of arsenic-bearing rocks in groundwater pollution at Zimapan Valley, México. Environ. Geol., 40:571-581.

Bigham J.M. \& Nordstrom D.K. 2000. Iron and hydroxysulfates from acid sulfate waters. In: C.N. Alpers, J.L. Jambor, D.K. Nordstrom (eds.) Sulfate minerals: crystallography, geochemistry and environmental significance. Reviews in mineralogy and geochemistry, 40, Mineralogical Society of America, pp.:351-403.

Borba R.P., Figueiredo B.F., Zambello F. 2003. Método quantitativo de análise do AsTotal, especiação do As em amostras de água: aplicação no monitoramento ambiental de As em água. In: SBGq, Cong. Bras. Geoq., 9, Anais, p: 313-315.

Bowell R.J. 1994. Sorption of arsenic by iron oxides and oxyhydroxides in soils. Appl. Geoch., 9:279-286.

Bowell R.J., Morley N.H., Din V.K. 1994. Arsenic speciation in soil porewaters from the Ashanti mine, Ghana. Appl. Geoch., 9:15-22.

Brookins, D.J. 1988. Eh-pH diagrams for geochemistry. Springer, Berlin, 176pp.
Cavalcanti J.A.D. 1999. Mineralização aurífera de Lages-Antônio Dias, Ouro Preto, Minas Gerais: Controles Lito-estratigráficos e Estruturais. Dissertação de Mestrado, IG-Unicamp, 108p.

Dorr II J. V. N. 1969. Physiographic, stratigraphic and structural development of the QF, Brazil. Washington, DNPM/USGS, Prof. Paper 641-A, $109 \mathrm{p}$.

Dove P.M. \& Rimstidt D. 1985. The solubility and stability of scorodite, $\mathrm{FeAsO}_{4} \cdot 2 \mathrm{H}_{2} \mathrm{O}$. Am. Min., 70:838-844.

Dzombak D.A. \& Morel F.M.M. 1990. Surface complexation modeling: hydrous ferric oxide. John Wiley and Sons, New York, 393p.

Fernandez M.G.M., Mustin C., Donato P., Barres O., Marion P., Berthelin J. 1995. Occurrences at mineral-bacteria interface during oxidation of arsopyrite by Thiobacillus ferrooxidans. Biotechnology and Bioengineering, 46:13-21.

Juillot F., Ildefonse Ph., Morin G., Calas G., Kersabiec A.M. 1999. Remobilization of arsenic from buried wastes at an industrial site: mineralogical and geochemical control. Appl. Geoch., 14:10311048.

Krause E. \& Ettel V.A. 1988. Solubility and stability of escorodita, $\mathrm{FeAsO}_{4} \cdot 2 \mathrm{H}_{2} \mathrm{O}$ : new data and further discussion. Am. Min., 73:850854.

Manning B.A. \& Goldberg S. 1996. Modeling arsenate competitive 
adsorption on kaolinite, montmorilonite and illite. Clays and Clay Minerals, 44:609-623.

Manning B.A. \& Goldberg S. 1997. Adsorption and stability of arsenic(III) at the clay mineral-water interface. Environ. Sci. Technol., 31:2005-2011.

McGuire M.M., Edwards K.J., Banfield J.F., Hamers R.J. 2001a. Kinetics, surface chemistry, and structural evolution of microbially mediated sulfide mineral dissolution. Geochem. Cosmoch. Acta, 65:12431258.

McGuire M.M., Jallad, K.N., Ben-Amotz, D., Hamers, R.J. 2001 b. Chemical mapping of elemental sulfur on pyrite and arsenopyrite surfaces using near-infrared Raman imaging microscopy. Applied Surface Science, 178: 105-115.

Mielke R. E., Pace D.L., Porter T., Southam G. 2003. A critical stage in the formation of acid mine drainage:Colonization of pyrite by Acidithiobacillus ferrooxidans under $\mathrm{pH}$-neutral conditions. Geobiology, 1:81-90.

Nesbitt H.W., Muir I.J., Pratt A.R. 1995. Oxidation of arsenopyryte by air and air-satured, distillide water, and implications for mechanism of oxidation. Geochem. Cosmoch. Acta, 59:1773-1786.

Nordstron D.K. \& Southam, G. 1997. Geomicrobiology of sulphide mineral oxidation. In:J.F Banfield. \& K.H. Nealson (eds.) Geomicrobiology - Interactions between microbes and minerals. Mineralogical Society of America, Washington, D.C., Reviews in Mineralogy, 35:361-390p.

Oliveira F.R. 1998. Contribuição ao estudo da geologia estrutural e da gênese do depósito aurífero de Passagem - MG. Dissertação de Mestrado, Instituto de Geociências, Unicamp, 127p.

Plumlee G.S. 1999. The environmental geology of mineral deposits. In: G.S. Plumlee \& M.J. Logsdon, (eds.) The environmental geochemistry of mineral deposits, Part A: Processes, techniques, and health issues. Society of Economic Geologists, Reviews in Economic Geology, 6:71-116.

Ribeiro R.K. 1998. Mineralogia, geoquímica e gênese das ocorrências auríferas no flanco norte do anticlinal de Mariana, Quadrilátero Ferrífero: uma nova tipologia de minério denominada Bugre. Dissertação de Mestrado, IG-UnB, 115p.

Richardson S. \& Vaughan, D.J. 1989. Arsenopyrite: a spectroscopic investigation of altered surfaces. Mineral. Mag., 53:223-229.

Smedley, P. 1996. Arsenic in groudwater in Ghana. J. African Earth Sciences, 22:459-470.

Smedley P.L. \& Kinniburgh D.G. 2002 A review of the source, behaviour and distribution of arsenic in natural waters Source and behaviour of arsenic in natural waters. Applied Geochem., 17:517-568

Stumm W. 1992. Chemistry of the solid-water interface: processes at the mineral-water and particle-water interface in natural systems. Willey, New York, 428p.

Stumm W. \& Morgan J.J. 1996. Aquatic chemistry: Chemical equilibria and rates in natural waters, 3rd edition. Willey, New York, 1022p.

Vink B.W. 1996. Stability relations of antimony and arsenic compounds in the light of revised and extended Eh-ph diagrams. Chem. Geol., 130:21-30.

Voigt D.E., Brantley S.L., Hennet R.J.C. 1996. Chemical Fixation of arsenic in contaminated soils. Applied Geochem., 11:633-643.

Welham N.J., Malatt K.A., Vukcevic S. 2000. The stability of iron phases presently used for disposal from metallurgical systems - a review. Minerals Engineering, 13:911-931.

Manusscrito A-1416

Recebido em 28 de fevereiro de 2003

Revisão dos autores em 15 de maio de 2004 Revisão aceita em 05 de junho de 2004 